\title{
Risk of pancreatic cancer among individuals with hepatitis C or hepatitis B virus infection: a nationwide study in Sweden
}

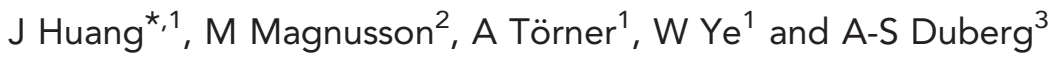 \\ ${ }^{1}$ Department of Medical Epidemiology and Biostatistics, Karolinska Institutet, 17177 Stockholm, Sweden; ${ }^{2}$ Department of Analysis \\ and Prevention, Swedish Institute for Communicable Disease Control, 17182 Solna, Sweden and ${ }^{3}$ Department of Infectious \\ Diseases, Örebro University Hospital, 70185 Örebro, Sweden
}

Background: A few studies indicated that hepatitis $\mathrm{C}$ and hepatitis B virus (HCV/HBV) might be associated with pancreatic cancer risk. The aim of this nationwide cohort study was to examine this possible association.

Methods: Hepatitis C virus- and hepatitis B virus-infected individuals were identified from the national surveillance database from 1990 to 2006, and followed to the end of 2008. The pancreatic cancer risk in the study population was compared with the general population by calculation of Standardized Incidence Ratios (SIRs), and with a matched reference population using a Cox proportional hazards regression model to calculate hazard ratios (HRs).

Results: In total 340819 person-years in the HCV cohort and 102295 in the HBV cohort were accumulated, with 34 and 5 pancreatic cancers identified, respectively. The SIR $\mathrm{HCV}_{\text {was }} 2.1$ (95\% confidence interval, $\left.\mathrm{Cl}: 1.4,2.9\right)$ and the $\mathrm{SIR}_{\mathrm{HBV}}$ was 1.4 $(0.5,3.3)$. In the Cox model analysis, the HR for HCV infection was $1.9(95 \% \mathrm{Cl}: 1.3,2.7)$, diminishing to $1.6(1.04,2.4)$ after adjustment for potential confounders.

Conclusion: Our results indicated that HCV infection might be associated with an increased risk of pancreatic cancer but further studies are needed to verify such association. The results in the HBV cohort indicated an excess risk, however, without statistical significance due to lack of power.

Pancreatic cancer is one of the most rapidly fatal malignancies with a 5 -year survival rate below $5 \%$. The long-term survival is poor also for early diagnosed patients treated with resection surgery (Jemal et al, 2010). In Europe, it was estimated in a prediction model that in the year 2012 there would be 75000-80000 deaths from pancreatic cancer, which is the fourth most common cause of cancer-associated death for both men and women (Malvezzi et al, 2012). The incidence of pancreatic cancer is higher in the Nordic countries and Central Europe than in other parts of the world (Bosetti et al, 2012).

Tobacco smoking is a well-established risk factor for pancreatic cancer (Iodice et al, 2008), and a similar magnitude of excess risk as smoking was found among the users of Scandinavian snus (moist snuff) (Boffetta et al, 2005; Luo et al, 2007). Besides, accumulating evidence consistently shows that old age, male sex, diabetes mellitus, hereditary pancreatitis, chronic pancreatitis and family history are positively associated with this carcinoma (Pandol et al, 2012). Albeit the biological mechanism is unclear, recent epidemiological studies indicated that some infections, such as exposure to Helicobacter pylori (Trikudanathan et al, 2011), poor oral health (Michaud et al, 2007), hepatitis C virus (HCV) (Hassan et al, 2008; El-Serag et al, 2009) or hepatitis B virus (HBV) (Hassan et al, 2008; Iloeje et al, 2010; Wang et al, 2012a,b) might be associated with pancreatic cancer risk.

Globally, $\sim 170$ million people are chronically infected with HCV (World Health Organization, 1997) and an estimated 350 
million with HBV (Custer et al, 2004). The prevalence rates of $\mathrm{HCV}$ and HBV infection vary widely in the world, and Sweden is a low endemic country with an estimated $0.5 \%$ of the population infected with HCV (Duberg et al, 2008a) and even lower rate for $\mathrm{HBV}$ infection. Both chronic HCV and HBV infections are main causes of hepatocellular carcinoma (HCC). Previous findings demonstrated that $\mathrm{HBV}$ may replicate within the pancreas (Shimoda et al, 1981; Yoshimura et al, 1981) and that HCV could be associated with pancreatitis (Alvares-Da-Silva et al, 2000; Torbenson et al, 2007). Some studies support that HCV and HBV may have a role in the development of pancreatic cancer, but the evidence is far from conclusive (Hassan et al, 2008; El-Serag et al, 2009; Iloeje et al, 2010; Wang et al, 2012a,b), and more studies are needed. Towards this end, we utilised Swedish population-based nationwide registers, with documentation of all diagnosed HCVand $\mathrm{HBV}$-infected individuals in Sweden, to explore the association of $\mathrm{HCV}$ or $\mathrm{HBV}$ infection and the risk of pancreatic cancer.

\section{MATERIALS AND METHODS}

Study population. The $\mathrm{HCV}$ and $\mathrm{HBV}$ cohorts have been described in detail in previous studies (Duberg et al, 2008b; Hofmann et al, 2011). Briefly, we identified all HCV and HBV infection notifications in Sweden from 1990 to the end of 2006, based on the records in the national surveillance database at the Swedish Institute for Infectious Disease Control (SMI), to generate our study cohorts. In Sweden, it is mandatory to report all diagnosed HCV and HBV infections to SMI since 1990 and 1969, respectively, and the notifications are delivered in parallel by the diagnosing laboratory and clinician and merged in the surveillance database using the personal identification number. The laboratory reports for $\mathrm{HCV}$ are based on positive $\mathrm{HCV}-\mathrm{RNA}$ or anti-HCV test (verified with immunoblot, HCV-core antigen, or HCV-RNA analyses) and for $\mathrm{HBV}$ on positive HBsAg or HBV-DNA. The clinical reports contain information such as probable route of transmission and for HBV infection also information about acute or chronic infection based on clinical information and medical history.

After excluding subjects with multiple notifications, erroneous documentation, incomplete personal follow-up data, as well as those with acute HBV infection $(N=2050)$, and those reported to both the $\mathrm{HCV}$ and the $\mathrm{HBV}$ register $(N=3556)$ to exclude coinfection, there were 39442 subjects with HCV infection forming the HCV cohort and 11511 individuals with chronic $\mathrm{HBV}$ infection in the HBV cohort.

A five times larger reference population was produced from the Population Register at Statistics Sweden (1:5 matching). For each $\mathrm{HCV}$ - or HBV-infected subject another five individuals who were never diagnosed with a $\mathrm{HCV}$ or $\mathrm{HBV}$ infection were randomly selected from the general population matched on year of birth, sex and county of residence in Sweden. This procedure formed a HCV reference cohort of 197208 individuals and a chronic HBV reference cohort of 57554 subjects. Each individual in the noninfected reference cohorts was assigned the same 'study entry' date as their matched infected individual, that is, the HCV or HBV notification date.

Linkage to other registers. The national registration number (NRN) is a unique personal identification number allocated to every Swedish resident. Via the NRNs, our cohort members were followed by cross linkages through Swedish registers, including the Population Register, Cause of Death Register, Cancer Register and the Inpatient Register, to obtain information on date of emigration, date and cause of death, any malignancies and hospital admissions for certain medical conditions.
Pancreatic cancer, as our main outcome, was ascertained from the Cancer Register (International Classification of Disease ICD-7: 157) for the principal analyses, but also from the Cause of Death Register (ICD-9: 157; ICD-10: C25) for some additional analyses.

From the Inpatient register hospitalisations with the discharge diagnoses of chronic obstructive pulmonary disease, diabetes mellitus, chronic pancreatitis and diagnoses related to alcohol abuse were identified (for ICD-codes, see Appendix Table A1). These medical conditions were considered as potential confounders or related to a confounder and therefore identified and adjusted for in some of the analyses.

For additional analyses also acute pancreatitis was identified from the Inpatient Register, and to further study the impact of smoking all incident lung cancers in the cohorts were ascertained from the Cancer Register (ICD-codes in Appendix Table A1).

Follow-up. The individuals in the cohorts were followed from the entry date, either their $\mathrm{HCV} / \mathrm{HBV}$ notification date or the corresponding assigned study entry date (noninfected reference population), until the date of first primary cancer diagnosis, emigration, death or the end of follow-up (31 December 2008), whichever came first.

To minimise the potential influence of selection bias, the first 6 months of follow-up for each patient were excluded in all final analyses. This lag time of 6 months was based on modelling the hazard after inclusion in the cohort using a restricted cubic spline model (Torner et al, 2011).

Statistical analyses. In the first statistical analysis, the risk for pancreatic cancer in the HCV cohort and in the HBV cohort was compared with the risk in the general population. This was measured as the Standardized Incidence Ratio (SIR), which is the ratio of the observed number of pancreatic cancer cases compared with the expected case number. For each cohort, the expected numbers were calculated from the observed person-time in each 5 -year age group by sex and the corresponding Swedish population incidence rates. Thus, in the SIR calculation, age of follow-up, sex and calendar year were inherently adjusted. Assuming that the number of observed pancreatic cancer cases followed a Poisson distribution, 95\% confidence intervals (CIs) were calculated according to the Max method (Kulkarni et al, 1998). Stratified analyses were performed by sex, infection duration, period and year of birth (before/after 1960). On the basis of an earlier developed model, duration of $\mathrm{HCV}$ infection at the time of notification was estimated according to age, suspected route of transmission and the epidemiology of $\mathrm{HCV}$ transmission in Sweden (Duberg et al, 2005).

In the second statistical analysis, to further evaluate the association, we utilised the Cox proportional hazards regression model to estimate hazard ratios (HRs) and the corresponding 95\% CIs. Pancreatic cancer risk in the HCV cohort and in the HBV cohort was compared with pancreatic cancer risk in the corresponding noninfected reference cohort. In these cohorts, the noninfected individuals were matched to the HCV- or HBVinfected patients by birth year, sex and county of Sweden; therefore, these variables were inherently adjusted in the models. Furthermore, adjustments for other potential confounders were applied in the Cox model, including hospitalisations for chronic obstructive pulmonary disease, diabetes mellitus, chronic pancreatitis and diagnoses related to alcohol abuse. However, concerning that diabetes mellitus or chronic pancreatitis might be consequences of pancreatic cancer, we ignored diabetes mellitus or chronic pancreatitis diagnoses within 5 years before pancreatic cancer diagnosis. Finally, we conducted an additional analysis stratified by sex.

Acute pancreatitis might be a complication to interferon therapy for $\mathrm{HCV}$ infection, and pancreatitis is reported to be a risk factor for pancreatic cancer. To exclude the possibility of iatrogenic risk, 
additional Cox regression analyses were made after exclusion of all patients who ever hospitalised for acute and/or chronic pancreatitis (in the HCV cohort: $n=1387$; in the HCV reference cohort: $n=1491)$.

The Swedish Cancer Register does not include the Death Certificate Only cases, thus some pancreatic cancers might be missed by only using the Cancer Register (Luo et al, 2008). Therefore, we further performed a Cox regression analysis including pancreatic cancer cases ascertained from the Cancer register and the Cause of Death Register.

In order to estimate the potential influence of smoking, similar analyses (SIR, HR) were conducted for lung cancer in parallel.

The R language for statistical computing (R Core Team, 2011) was used for both data preparation and the statistical analyses. For the statistical analyses, the R-package 'survival' (Therneau, 2011) was used together with Lexis objects (Martyn Plummer, 2011) in the 'Epi' R-package (Carstensen et al, 2011).

Ethical approval. The study was approved by the Regional Ethical Review Board in Stockholm, Sweden. To ensure the data confidentiality, the personal identification numbers were deleted after the record linkage and before the analysis.

\section{RESULTS}

Baseline characteristics of the HCV and HBV cohorts are presented in Table 1. In the HCV and chronic HBV cohorts the mean follow-up time were 9.1 and 9.4 years, with a total of 360154 and 107986 person-years at risk, respectively. There was a clear

Table 1. Characteristics of the study population, the chronic hepatitis $B$ virus (HBV) infection and the hepatitis C virus ( $\mathrm{HCV}$ ) infection cohorts

\begin{tabular}{|l|c|c|}
\hline & $\begin{array}{c}\text { Chronic HBV } \\
\text { cohort }^{\text {a }}, \mathbf{N}(\%)\end{array}$ & $\begin{array}{c}\text { HCV } \text { cohort }^{\text {b }} \\
\mathbf{N}(\%)\end{array}$ \\
\hline Number in cohort & 11511 & 39,442 \\
\hline Deceased & $738(6.4)$ & $7872(20.0)$ \\
\hline Emigrated & $780(6.8)$ & $1326(3.4)$ \\
\hline $\begin{array}{l}\text { Person-years accumulated } \\
\text { during follow-up }\end{array}$ & 107986 & 360154 \\
\hline Mean follow-up time, years & 9.4 & 9.1 \\
\hline Male sex \% & $6117(53.1)$ & $27024(68.5)$ \\
\hline $\begin{array}{l}\text { Median age at HBV/HCV } \\
\text { notification (male, female) }\end{array}$ & $31(33,29)$ & $38(38,37)$ \\
\hline Year of birth, median (range) & $1967(1906,2006)$ & $1958(1898,2006)$
\end{tabular}

\section{Country of origin}

Nordic countries

Non-Nordic European countries

$1779(15.5)$

$3166(27.5)$

Other

$6482(56.3)$

Suspected route of virus transmission

Intravenous drug use

Blood/blood products

Sexual contact

Nosocomial transmission

Mother-child

Other

Unknown or missing

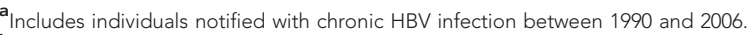

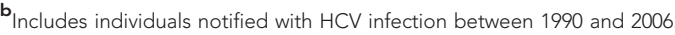

$130(0.3)$

$92(0.2)$
$35033(88.8)$

$2035(5.2)$

$2305(5.8)$

male dominance in the $\mathrm{HCV}$ cohort, and median age at entry into the HCV or HBV cohorts (notification date) was 38 and 31 years, respectively. A marked difference between cohorts was observed regarding the aspect of country of origin; $\mathrm{HCV}$-infected individuals were more likely from Nordic countries, but persons with chronic HBV infection were often immigrants from non-Nordic countries.

Hepatitis C virus cohort. In the $\mathrm{HCV}$ cohort, there were 34 pancreatic cancer cases observed during 340819 person-years of follow-up (first 6 months of follow-up excluded), whereas 16.5 were expected, yielding a statistically significant increased risk of pancreatic cancer (SIR: 2.1; 95\% CI: 1.4, 2.9). The SIR did not alter substantially across sex or estimated duration of HCV infection (Table 2). The majority of cases were among the patients who were born before 1960 .

From the Cox regression model, an $~ 90 \%$ excessive risk for pancreatic cancer (HR 1.9; 95\% CI: 1.3, 2.7) was observed after adjustment for age, sex and county of residence, which is similar to the result from the SIR analysis. This excess risk diminished somewhat but remained statistically significant after further adjustment for potential confounders (HR 1.6; 95\% CI: 1.04, 2.4). The results did not vary markedly when stratified by sex (Table 3 ). In the additional analyses, excluding all individuals ever hospitalised with acute and/or chronic pancreatitis, the results did not alter notably (data not shown).

In the HCV cohort, the SIR for lung cancer was 2.3 (95\% CI: 1.9, 2.7) and the $\mathrm{HR}$ for lung cancer was 2.2 (95\% CI: 1.8, 2.7), decreasing to 1.6 (95\% CI: 1.3, 2.1) after adjustment for the potential confounders used in the pancreatic cancer analyses.

Chronic HBV cohort. A total of five pancreatic cancer cases were found during 102295 person-years of follow-up (first 6 months excluded), whereas 3.5 were expected. Compared with the age- and sex-matched Swedish general population, a $40 \%$ excess risk of

Table 2. Standardized Incidence Ratio (SIR) for pancreatic cancer among 39442 individuals infected with hepatitis $\mathrm{C}$ virus (HCV) compared with the general population

\begin{tabular}{|l|l|l|l|l|}
\cline { 2 - 5 } & \multicolumn{4}{|c|}{ Pancreatic cancer } \\
\cline { 2 - 5 } & $\mathrm{O}^{\mathrm{a}}$ & $\mathrm{E}^{\mathrm{b}}$ & SIR & $95 \% \mathrm{CI}$ \\
\hline
\end{tabular}

Lag period after HCV notification

\begin{tabular}{|l|c|c|c|c|}
\hline \$6 Months & 4 & 0.8 & 5.3 & $(1.4,13.5)$ \\
> Months & 34 & 16.5 & 2.1 & $(1.4,2.9)$ \\
\hline
\end{tabular}

Sex-stratified analysis ${ }^{c}$

\begin{tabular}{|l|c|c|c|c|}
\hline Men & 23 & 11.5 & 2.0 & $(1.3,3.0)$ \\
Women & 11 & 5.0 & 2.2 & $(1.1,3.9)$ \\
\hline
\end{tabular}

HCV duration ${ }^{c, d}$

\begin{tabular}{|l|c|c|c|c|}
\hline$\leqslant 20$ Years & 10 & 5.4 & 1.9 & $(0.9,3.4)$ \\
$>20$ Years & 24 & 11.1 & 2.2 & $(1.4,3.2)$ \\
\hline
\end{tabular}

Year of birth ${ }^{c}$

Before 1960

From 1960

\begin{tabular}{c|c}
\hline 31 & 15.5 \\
3 & 1.0 \\
\hline
\end{tabular}

2.0

$(1.4,2.8)$

848 (2.1)

$13117(33.3)$

Abbreviation: $\mathrm{Cl}=$ confidence interval

${ }^{a}$ Observed number of pancreatic cancer cases.

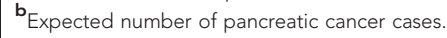

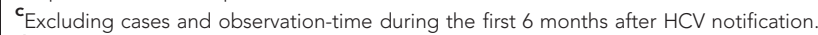

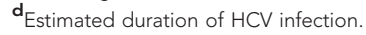




\begin{tabular}{|c|c|c|c|}
\hline & \multicolumn{3}{|c|}{ Pancreatic cancer } \\
\hline & Cases & HR & $95 \% \mathrm{Cl}$ \\
\hline Total & 154 & & \\
\hline $\begin{array}{l}\text { Non-HCV infection } \\
\text { HCV infection } \\
\text { HCV infection }\end{array}$ & $\begin{array}{c}120 \\
34 \\
34\end{array}$ & $\begin{array}{l}1.0 \\
1.9 \\
1.6\end{array}$ & $\begin{array}{c}(1.3,2.7) \\
(1.04,2.4)\end{array}$ \\
\hline \multicolumn{4}{|l|}{ Sex } \\
\hline Men, total & 99 & & \\
\hline $\begin{array}{l}\text { Non-HCV infection } \\
\text { HCV infection } \\
\text { HCV infection } \\
\text { b,c }\end{array}$ & $\begin{array}{l}76 \\
23 \\
23\end{array}$ & $\begin{array}{l}1.0 \\
2.0 \\
1.7\end{array}$ & $\begin{array}{c}(1.2,3.2) \\
(1.02,3.0)\end{array}$ \\
\hline Women, total & 55 & & \\
\hline $\begin{array}{l}\text { Non-HCV infection } \\
\text { HCV infection } \\
\text { HCV infection }\end{array}$ & $\begin{array}{l}44 \\
11 \\
11\end{array}$ & $\begin{array}{l}1.0 \\
1.7 \\
1.4\end{array}$ & $\begin{array}{l}(0.9,3.2) \\
(0.7,2.9)\end{array}$ \\
\hline \multicolumn{4}{|c|}{$\begin{array}{l}\text { Abbreviation: } \mathrm{Cl}=\text { confidence interval. } \\
\mathrm{a}_{\text {First }} 6 \text { months of follow-up after } \mathrm{HCV} \text { notification were excluded. } \\
\mathrm{b}_{\text {Inherently adjusted for birth year, sex and county of residence in the model. }} \\
{ }^{c} \text { Adjusted for chronic obstructive pulmonary disease, diabetes mellitus, chronic pancreatitis } \\
\text { and alcohol-related diseases. }\end{array}$} \\
\hline
\end{tabular}

Table 4. Standardized Incidence Ratio (SIR) for pancreatic cancer among 11511 individuals with chronic hepatitis B virus (HBV) infection compared with the general population

\begin{tabular}{|c|c|c|c|c|}
\hline & \multicolumn{4}{|c|}{ Pancreatic cancer } \\
\hline & $\mathrm{O}^{\mathrm{a}}$ & $\mathrm{E}^{\mathrm{b}}$ & SIR & $95 \% \mathrm{Cl}$ \\
\hline \multicolumn{5}{|c|}{ Lag period after HBV notification } \\
\hline $\begin{array}{l}\leqslant 6 \text { Months } \\
>6 \text { Months }\end{array}$ & $\begin{array}{l}3 \\
5\end{array}$ & $\begin{array}{l}0.2 \\
3.5\end{array}$ & $\begin{array}{c}19.5 \\
1.4\end{array}$ & $\begin{array}{c}(4.0,57.1) \\
(0.5,3.3)\end{array}$ \\
\hline \multicolumn{5}{|c|}{ Sex-stratified analysis ${ }^{c}$} \\
\hline $\begin{array}{l}\text { Men } \\
\text { Women }\end{array}$ & $\begin{array}{l}4 \\
1\end{array}$ & $\begin{array}{l}2.2 \\
1.3\end{array}$ & $\begin{array}{l}1.8 \\
0.8\end{array}$ & $\begin{array}{c}(0.5,4.6) \\
(0.02,4.3)\end{array}$ \\
\hline \multicolumn{5}{|c|}{ 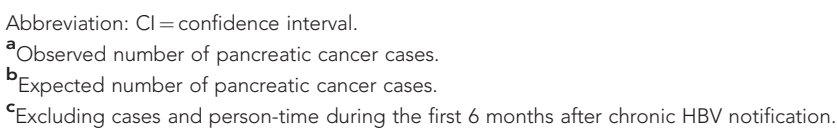 } \\
\hline
\end{tabular}

pancreatic cancer was found in the chronic HBV cohort (SIR: 1.4; 95\% CI: 0.5, 3.3), but without statistical significance. Because of the small number of pancreatic cancer cases, there was not enough power for additional stratified analyses (Table 4).

The Cox regression model revealed similar results as the SIR analysis. The point estimates were somewhat higher $(\mathrm{HR}=2.0$ from the model adjusted for only matching factors and $\mathrm{HR}=1.8$ from the fully adjusted model), but still statistically non-significant (Table 5). The SIR for lung cancer in the chronic HBV infection cohort was 1.7 (95\% CI: 1.1, 2.5).

Additional analyses. To rule out the impact of pancreatic cancer cases missing in the Cancer Registry, additional analyses (Cox regression model) were performed including both Cancer Register

\begin{tabular}{|c|c|c|c|}
\hline \multicolumn{4}{|c|}{$\begin{array}{l}\text { Table } 5 \text {. Hazard ratios (HRs) of pancreatic cancer associated with chronic } \\
\text { hepatitis B virus (HBV) infection }{ }^{\text {a }}\end{array}$} \\
\hline & \multicolumn{3}{|c|}{ Pancreatic cancer } \\
\hline & Cases & HR & $95 \% \mathrm{Cl}$ \\
\hline Total & 21 & & \\
\hline $\begin{array}{l}\text { Non-HBV infection } \\
\text { HBV infection }{ }^{\mathbf{b}} \\
\text { HBV infection }{ }^{b, c}\end{array}$ & $\begin{array}{c}16 \\
5 \\
5\end{array}$ & $\begin{array}{l}1.00 \\
2.0 \\
1.8\end{array}$ & $\begin{array}{l}(0.7,5.3) \\
(0.7,5.1)\end{array}$ \\
\hline \multicolumn{4}{|c|}{$\begin{array}{l}\text { Abbreviation: } \mathrm{Cl}=\text { confidence interval. } \\
\mathrm{a}_{\text {First }} 6 \text { months of follow-up after HBV notification were excluded. } \\
\mathbf{b}_{\text {Inherently adjusted for birth year, sex and county of residence in the model. }} \\
{ }^{c} \text { Adjusted for chronic obstructive pulmonary disease, diabetes mellitus, chronic pancreatitis } \\
\text { and alcohol-related diseases. }\end{array}$} \\
\hline
\end{tabular}

and Death Certificate Only pancreatic cancers (HCV cohort: $n=77$; chronic HBV cohort: $n=20$ ). The main results did not alter appreciably (HR for HCV infection: 1.9, 95\% CI: 1.4, 2.6; other data not shown).

\section{DISCUSSION}

This population-based large cohort study revealed a doubled risk of pancreatic cancer among HCV-infected patients compared with the Swedish general population. The excess risk was persistent across strata by sex or duration of infection. Although further adjustment for potential confounders, i.e., chronic obstructive pulmonary disease (related to smoking), diabetes mellitus, chronic pancreatitis and alcohol-related disease, resulted in an attenuated relative risk, this finding still supports the hypothesis that $\mathrm{HCV}$ infection might be associated with an increased risk of pancreatic cancer. Besides, the result indicated a moderate excessive risk of pancreatic cancer among $\mathrm{HBV}$-infected patients according to different statistical approaches, but the size of the study cohort and the observed number of cancers were too small to draw a sound conclusion. Pancreatic cancer is more common in older age groups, and the small number of pancreatic cancers among the HBV cohort was probably an effect of the relatively young cohort, concordant with the epidemiology of chronic hepatitis $B$ in Sweden.

The strengths of this register-based study include populationbased cohort design, relatively large sample size, independently collected data on documentation of $\mathrm{HCV} / \mathrm{HBV}$ notifications and pancreatic cancer occurrence and high completeness of follow-up. However, some limitations need to be discussed.

Tobacco use is an established risk factor and cigarette smokers have a doubled risk for pancreatic cancer (Bosetti et al, 2012). In this study, it was impossible to identify smokers but possible to identify subjects diagnosed with chronic obstructive pulmonary disease (a smoking-related disease). Besides, diabetes mellitus, chronic pancreatitis and heavy alcohol consumption are possible risk factors for pancreatic cancer (Ye et al, 2002; Torbenson et al, 2007; Ben et al, 2011) that might bias the association between $\mathrm{HCV}$ infection and pancreatic cancer risk. To allay these concerns, we adjusted for chronic obstructive pulmonary disease, diabetes mellitus, chronic pancreatitis as well as alcohol-related disease strongly correlated to heavy alcohol consumption in the Cox regression model. Although slightly attenuated, the HRs for pancreatic cancer did not alter remarkably after adjustment for these potential confounding factors. In order to get further insight 
into potential effects of smoking, the SIR and HR for lung cancer were calculated. A doubled risk of lung cancer in the HCV cohort indicated that smoking was more common than in the general population. The HR for lung cancer decreased to 1.6 after adjustment for the potential confounders also used in the pancreatic cancer analyses, strengthening the use of these diagnoses as surrogate markers for smoking. After adjustment the HRs were attenuated but still increased at the similar magnitude for pancreatic cancer and lung cancer, indicating that smoking was not the only explanation of the increased risk for pancreatic cancer in the $\mathrm{HCV}$ cohort. If this finding was explained only by smoking the HR of lung cancer in the HCV cohort probably should have been higher, as in previous studies the relative risk of lung cancer was $\sim 10$ among smokers compared with non-smokers (Pesch et al, 2012), whereas that for pancreatic cancer was around two-fold (Bosetti et al, 2012). Furthermore, based on Walker's finding (Walker, 1991), the confounding effect size is usually rather small even when both the exposure-covariate relationship and confounder-disease relationship are strong. For instance, in order to completely bias the exposure effect of 1.4 by a pure confounding of smoking, it requires that both the association between smoking and $\mathrm{HCV} / \mathrm{HBV}$ infection as well as smoking and pancreatic cancer are larger than 3.

Acute pancreatitis could possibly be a complication of interferon therapy (Chaudhari et al, 2004) and might act as a potential mediator in the pathway between HCV infection and pancreatic cancer. To exclude the possibility of iatrogenic risk, additional analyses were performed excluding all individuals ever hospitalised with pancreatitis (acute and chronic), but the results did not alter notably.

Another potential risk factor for pancreatic cancer is the use of Scandinavian snus (Boffetta et al, 2005; Luo et al, 2007), which is a common habit in Sweden; Statistics Sweden reported in 2012 that, irrespective of socioeconomic status, $20-25 \%$ of men were snususers. We have no information about the prevalence of snus-users in the HCV or HBV cohort.

In the relatively young $\mathrm{HBV}$ cohort, the sample size and the number of observed cancers were too small to draw a sound conclusion, not to mention further stratified analyses. An issue that needs to be addressed is that the majority of HBV-infected patients originated from non-Nordic countries, 37\% from former Yugoslavia and $32 \%$ from Asia. This probably resulted in an underestimation of the relative pancreatic cancer risk in this cohort given the fact that pancreatic cancer incidence has been reported higher among Swedes than immigrants (Mousavi et al, 2010). However, we were unable to match the HBV-infected patients and the reference population on their country of birth.

The parallel (laboratory and clinician) notification system of $\mathrm{HCV} / \mathrm{HBV}$ infections in Sweden has a high coverage of those with a diagnosed infection; it is estimated that about $75-80 \%$ of $\mathrm{HCV}$ infections are diagnosed, but there still remain unknown infections, not yet diagnosed or documented. In addition, a small portion of the reported patients could have a resolved infection, spontaneously or by treatment, this could (probably insignificant) lower the risk in the HCV and HBV cohort.

The number of unidentified $\mathrm{HCV} / \mathrm{HBV}$-coinfected individuals is probably low in the studied cohorts. However, in the HCV cohort there could be some patients who were never diagnosed with hepatitis B but have serologic markers of a past HBV infection. In these patients we cannot exclude the possibility of occult hepatitis $B$.

The biological mechanism of the association between HCV and pancreatic cancer is unclear. However, virtually, the pancreas and liver share the common blood vessels and ducts, and prior evidence demonstrated that the pancreas is a remote location for hepatitis virus inhabitation and replication (Hassan et al, 2008). HCV infection is associated with type 2 diabetes, which is both a risk factor and might be a consequence of pancreatic cancer (Mehta et al, 2000; Sangiorgio et al, 2000). Besides, previous studies reported that subclinical/acute pancreatitis (Katakura et al, 2005) and hyperlipasemia (Yoffe et al, 2003) may be extrahepatic manifestations of HCV infection. In addition, pancreatic involvement was observed among patients who suffered from chronic hepatitis infection, resulting in mild pancreatic damage accompanied with increased serum levels of pancreatic enzyme (Taranto et al, 1989; Katakura et al, 2005). Immune response may lead to chronic inflammation in the targeted organs after long time persistent infection with HCV. Therefore, hepatitis $\mathrm{C}$ virus conceivably serves as a biological agent that may indirectly have a role in inflammation-associated pancreatic carcinogenesis. Although still unclear to what extent chronic inflammation contributes to pancreatic cancer development, it is postulated that $\mathrm{HCV}$ can induce inflammatory microenvironment with high concentration of growth factors and cytokines. This may exert effects by accumulating alterations in driver genes and promoting cancer cell growth and proliferation. To date, very few epidemiologic studies have explored the association between $\mathrm{HCV}$ and pancreatic cancer. In the US veterans cohort study (El-Serag et al, 2009), a significant association between HCV and pancreatic cancer was first found but was attenuated after adjusting for alcohol consumption, pancreatitis and some other potential confounders. In a case-control study, Hassan et al (2008) found that the prevalence of HCV antibodies was not significantly higher among patients with pancreatic cancer $(1.5 \%)$ than controls (1\%). In our cohort study we found a doubled risk for pancreatic cancer in the HCV cohort, somewhat attenuated after adjustment for confounders but still statistically significant, indicating that $\mathrm{HCV}$ may have a role in the pancreatic carcinogenesis.

The role of HBV in carcinogenesis is not totally understood. Earlier studies proposed that HBV may replicate in the pancreas, based on the facts of detection of HBsAg in pancreatic juice (Hoefs et al, 1980), the detection of HBsAg and HBV core antigen in the pancreas acinar cells (Yoshimura et al, 1981), and verification of HBV-DNA integration in pancreatic tissue (Dejean et al, 1984). As mentioned, it has been hypothesised that long-term chronic HBV infection, concurrent with damage of pancreatic epithelial cells, results in an inflammatory response and consequently has a role in pancreatic cancer development (Taranto et al, 1989).

Some epidemiologic studies have investigated the association between $\mathrm{HBV}$ infection and pancreatic cancer risk. In a casecontrol study, Hassan et al (2008) reported a significantly increased prevalence of past exposure to HBV, but not current or chronic infection, in patients with pancreatic cancer compared with controls. In contrast, the REVEAL-HBV cohort study and a recent Chinese case-control study suggested that an increased risk of pancreatic cancer was associated with chronic HBV infection (Iloeje et al, 2010; Ben et al, 2012). In a recent meta-analysis, it was reported that inactive $\mathrm{HBsAg}$ carrier status and possible occult $\mathrm{HBV}$ infection may elevate the risk of pancreatic cancer (Wang et al, 2012b). In our study, point estimates favoured a positive association between $\mathrm{HBV}$ infection and pancreatic cancer risk, but due to a limited study power none of the observed associations were statistically significant.

In conclusion, this nationwide population-based cohort study demonstrated an increased risk of pancreatic cancer among HCVinfected individuals, although this excess risk was attenuated but still statistically significant after adjustment for other potential risk factors. Our results support the hypothesis that HCV infection might be associated with an increased risk of pancreatic cancer, but further studies, with more complete information about other potential confounding factors, are needed to verify the association and to explore the causality. 


\section{ACKNOWLEDGEMENTS}

The study was supported by grants from Nyckelfonden, Örebro, Sweden (11/007) and from Örebro County Council Research Committee (OLL-239191). JH was supported by a scholarship from the Karolinska Institutet (KID) and research grants from the Swedish Research Council (SIMSAM grant number 80748301). Guarantor of the article: Ann-Sofi Duberg.

\section{CONFLICT OF INTEREST}

The authors declare no conflict of interest.

\section{REFERENCES}

Alvares-Da-Silva MR, Francisconi CF, Waechter FL (2000) Acute hepatitis C complicated by pancreatitis: another extrahepatic manifestation of hepatitis C virus? J Viral Hepat 7(1): 84-86.

Ben Q, Li Z, Liu C, Cai Q, Yuan Y, Wang K, Xiao L, Gao J, Zhang H (2012) Hepatitis $\mathrm{B}$ virus status and risk of pancreatic ductal adenocarcinoma: a case-control study from China. Pancreas 41(3): 435-440.

Ben Q, Xu M, Ning X, Liu J, Hong S, Huang W, Zhang H, Li Z (2011) Diabetes mellitus and risk of pancreatic cancer: A meta-analysis of cohort studies. Eur J Cancer 47(13): 1928-1937.

Boffetta P, Aagnes B, Weiderpass E, Andersen A (2005) Smokeless tobacco use and risk of cancer of the pancreas and other organs. Int J Cancer 114(6) 992-995.

Bosetti C, Bertuccio P, Negri E, La Vecchia C, Zeegers MP, Boffetta P (2012) Pancreatic cancer: overview of descriptive epidemiology. Mol Carcinog 51(1): 3-13.

Carstensen B, Laara E, Hills M (2011) Epi: A Package for Statistical Analysis in Epidemiology. $R$ package version 1.1.24.

Chaudhari S, Park J, Anand BS, Pimstone NR, Dieterich DT, Batash S, Bini EJ (2004) Acute pancreatitis associated with interferon and ribavirin therapy in patients with chronic hepatitis C. Dig Dis Sci 49(6): 1000-1006.

Custer B, Sullivan SD, Hazlet TK, Iloeje U, Veenstra DL, Kowdley KV (2004) Global epidemiology of hepatitis B virus. J Clin Gastroenterol 38(10 Suppl 3): S158-S168.

Dejean A, Lugassy C, Zafrani S, Tiollais P, Brechot C (1984) Detection of hepatitis B virus DNA in pancreas, kidney and skin of two human carriers of the virus. J Gen Virol 65(Pt 3): 651-655.

Duberg A, Janzon R, Back E, Ekdahl K, Blaxhult A (2008a) The epidemiology of hepatitis C virus infection in Sweden. Euro Surveill 13(21): pii: 18882.

Duberg AS, Nordstrom M, Torner A, Reichard O, Strauss R, Janzon R, Back E, Ekdahl K (2005) Non-Hodgkin's lymphoma and other nonhepatic malignancies in Swedish patients with hepatitis $\mathrm{C}$ virus infection. Hepatology 41(3): 652-659.

Duberg AS, Torner A, Davidsdottir L, Aleman S, Blaxhult A, Svensson A, Hultcrantz R, Back E, Ekdahl K (2008b) Cause of death in individuals with chronic HBV and/or HCV infection, a nationwide community-based register study. J Viral Hepat 15(7): 538-550.

El-Serag HB, Engels EA, Landgren O, Chiao E, Henderson L, Amaratunge HC, Giordano TP (2009) Risk of hepatobiliary and pancreatic cancers after hepatitis $\mathrm{C}$ virus infection: A population-based study of US veterans. Hepatology 49(1): 116-123.

Hassan MM, Li D, El-Deeb AS, Wolff RA, Bondy ML, Davila M, Abbruzzese JL (2008) Association between hepatitis B virus and pancreatic cancer. J Clin Oncol 26(28): 4557-4562.

Hoefs JC, Renner IG, Askhcavai M, Redeker AG (1980) Hepatitis B surface antigen in pancreatic and biliary secretions. Gastroenterology 79(2): 191-194.

Hofmann JN, Torner A, Chow WH, Ye W, Purdue MP, Duberg AS (2011) Risk of kidney cancer and chronic kidney disease in relation to hepatitis $\mathrm{C}$ virus infection: a nationwide register-based cohort study in Sweden. Eur I Cancer Prev 20(4): 326-330.

Iloeje UH, Yang HI, Jen CL, Su J, Wang LY, You SL, Lu SN, Chen CJ (2010) Risk of pancreatic cancer in chronic hepatitis B virus infection: data from the REVEAL-HBV cohort study. Liver Int 30(3): 423-429.
Iodice S, Gandini S, Maisonneuve P, Lowenfels AB (2008) Tobacco and the risk of pancreatic cancer: a review and meta-analysis. Langenbecks Arch Surg 393(4): 535-545.

Jemal A, Siegel R, Xu J, Ward E (2010) Cancer statistics, 2010. CA Cancer J Clin 60(5): 277-300.

Katakura Y, Yotsuyanagi H, Hashizume K, Okuse C, Okuse N, Nishikawa K, Suzuki M, Iino S, Itoh F (2005) Pancreatic involvement in chronic viral hepatitis. World J Gastroenterol 11(23): 3508-3513.

Kulkarni PM, Tripathi RC, Michalek JE (1998) Maximum ( ${ }_{\text {Max }}$ ) and Mid-P confidence intervals and $P$ values for the standardized mortality and incidence ratios. Am J Epidemiol 147(1): 83-86.

Luo J, Adami HO, Reilly M, Ekbom A, Nordenvall C, Ye W (2008) Interpreting trends of pancreatic cancer incidence and mortality: a nation-wide study in Sweden (1960-2003). Cancer Causes Control 19(1): 89-96.

Luo J, Ye W, Zendehdel K, Adami J, Adami HO, Boffetta P, Nyren O (2007) Oral use of Swedish moist snuff (snus) and risk for cancer of the mouth, lung, and pancreas in male construction workers: a retrospective cohort study. Lancet 369(9578): 2015-2020.

Malvezzi M, Bertuccio P, Levi F, La Vecchia C, Negri E (2012) European cancer mortality predictions for the year 2012. Ann Oncol 23(4): 1044-1052.

Martyn Plummer BC (2011) Lexis: An R Class for epidemiological studies with long-term follow-up. J Stat Software 38(5): 1-12.

Mehta SH, Brancati FL, Sulkowski MS, Strathdee SA, Szklo M, Thomas DL (2000) Prevalence of type 2 diabetes mellitus among persons with hepatitis C virus infection in the United States. Ann Intern Med 133(8): 592-599.

Michaud DS, Joshipura K, Giovannucci E, Fuchs CS (2007) A prospective study of periodontal disease and pancreatic cancer in US male health professionals. J Natl Cancer Inst 99(2): 171-175.

Mousavi SM, Sundquist J, Hemminki K (2010) Does immigration play a role in the risk of pancreatic cancer? A study on immigrants to Sweden. Pancreas 39(7): 1118-1120.

Pandol S, Gukovskaya A, Edderkaoui M, Dawson D, Eibl G, Lugea A (2012) Epidemiology, risk factors, and the promotion of pancreatic cancer: role of the stellate cell. J Gastroenterol Hepatol 27(Suppl 2): 127-134.

Pesch B, Kendzia B, Gustavsson P, Jockel KH, Johnen G, Pohlabeln H, Olsson A, Ahrens W, Gross IM, Bruske I, Wichmann HE, Merletti F, Richiardi L, Simonato L, Fortes C, Siemiatycki J, Parent ME, Consonni D, Landi MT, Caporaso N, Zaridze D, Cassidy A, Szeszenia-Dabrowska N, Rudnai P, Lissowska J, Stucker I, Fabianova E, Dumitru RS, Bencko V, Foretova L, Janout V, Rudin CM, Brennan P, Boffetta P, Straif K, Bruning T (2012) Cigarette smoking and lung cancer-relative risk estimates for the major histological types from a pooled analysis of case-control studies. Int J Cancer 131(5): 1210-1219.

R Core Team (2011) R: A Language and Environment for Statistical Computing. R Foundation for Statistical Computing: Vienna, Austria.

Sangiorgio L, Attardo T, Gangemi R, Rubino C, Barone M, Lunetta M (2000) Increased frequency of $\mathrm{HCV}$ and $\mathrm{HBV}$ infection in type 2 diabetic patients. Diabetes Res Clin Pract 48(2): 147-151.

Shimoda T, Shikata T, Karasawa T, Tsukagoshi S, Yoshimura M, Sakurai I (1981) Light microscopic localization of hepatitis B virus antigens in the human pancreas. Possibility of multiplication of hepatitis B virus in the human pancreas. Gastroenterology 81(6): 998-1005.

Taranto D, Carrato A, Romano M, Maio G, Izzo CM, Del Vecchio Blanco C (1989) Mild pancreatic damage in acute viral hepatitis. Digestion 42(2): 93-97.

Therneau T (2011) Survival: Survival analysis, including penalised likelihood. $R$ package version 2: 36-39.

Torbenson M, Yeh MM, Abraham SC (2007) Bile duct dysplasia in the setting of chronic hepatitis C and alcohol cirrhosis. Am J Surg Pathol 31(9): 1410-1413.

Torner A, Dickman P, Duberg AS, Kristinsson S, Landgren O, Bjorkholm M, Svensson A (2011) A method to visualize and adjust for selection bias in prevalent cohort studies. Am J Epidemiol 174(8): 969-976.

Trikudanathan G, Philip A, Dasanu CA, Baker WL (2011) Association between Helicobacter pylori infection and pancreatic cancer. A cumulative meta-analysis. JOP 12(1): 26-31.

Walker AM (1991) Observation and Inference. An Introduction to the Methods of Epidemiology. Epidemiology Resources Inc, Publishers: Newton, MA, USA. 
Wang DS, Chen DL, Ren C, Wang ZQ, Qiu MZ, Luo HY, Zhang DS, Wang FH, Li YH, Xu RH (2012a) ABO blood group, hepatitis B viral infection and risk of pancreatic cancer. Int J Cancer 131(2): 461-468.

Wang Y, Yang S, Song F, Cao S, Yin X, Xie J, Tu X, Xu J, Xu X, Dong X, Lu Z (2012b) Hepatitis B virus status and the risk of pancreatic cancer: a meta-analysis. Eur J Cancer Prev 22(4): 328-334.

World Health Organization (1997) Hepatitis C: global prevalence. Wkly Epidemiol Rec 72(46): 341-344.

Ye W, Lagergren J, Weiderpass E, Nyren O, Adami HO, Ekbom A (2002) Alcohol abuse and the risk of pancreatic cancer. Gut 51(2): 236-239.
Yoffe B, Bagri AS, Tran T, Dural AT, Shtenberg KM, Khaoustov VI (2003) Hyperlipasemia associated with hepatitis C virus. Dig Dis Sci 48(8): 1648-1653.

Yoshimura M, Sakurai I, Shimoda T, Abe K, Okano T, Shikata T (1981) Detection of HBsAg in the pancreas. Acta Pathol Jpn 31(4): 711-717.

This work is published under the standard license to publish agreement. After 12 months the work will become freely available and the license terms will switch to a Creative Commons AttributionNonCommercial-Share Alike 3.0 Unported License.

\section{APPENDIX}

\section{Table A1. Covarieties definitions by ICD-7 to ICD-10 codes}

\begin{tabular}{|l|c|c|c|c|}
\hline & ICD-7 codes & ICD-8 codes & ICD-9 codes & ICD-10 codes \\
\hline Pancreatic cancer & $157^{\mathbf{a}}$ & 157 & $157^{\mathbf{b}}$ & $\mathrm{C}^{\mathbf{b}}$ \\
\hline Lung cancer & $1621^{\mathbf{a}}$ & 162 & $162^{\mathbf{b}}$ & $\mathrm{C}^{\mathbf{b}}$ \\
\hline Chronic obstructive pulmonary disease & & 491 & 491 & $\mathrm{~J} 44$ \\
\hline Diabetes mellitus & & 250 & 250 & E10, E11, E12, E13, E14 \\
\hline Chronic pancreatitis & & $577.10,577.19$ & $577 \mathrm{~B}$ & K86 \\
\hline Acute pancreatitis & & 577.0 & $577 \mathrm{~A}$ & F10, T51 \\
\hline Alcohol abuse & & 291,303 & $291,303,305 \mathrm{~A}, \mathrm{V79B}$ & \\
\hline
\end{tabular}

Abbreviation: $I C D=$ International Classification of Disease.

a Use Cancer Register for identification.

bUse Cause of Death Register for identification. 